\title{
Fire Spread between Industrial Premises
}

\author{
HAUKUR INGASON and ANDERS LÖNNERMARK \\ SP Technical Research Institute of Sweden \\ Fire Technology \\ Borås, Sweden
}

\begin{abstract}
The study focuses on investigating models for calculating the risks of fire spread from an industrial building to adjacent buildings. The basic parameters necessary to determine the risk of fire spread are the flame height and the incident heat flux. There is limited information found about flame heights from industrial buildings where the fire breaks through the ceiling. Calculation methods for flame heights and incident heat fluxes are discussed and compared to model-scale data and large-scale data. A series of model-scale tests with flames through openings in a building where flashover has occurred are presented and compared to flame height correlations. This paper provides new data and a better understanding of the necessary input for such calculations. The model-scale tests show a good correspondence between a simple method to calculate heat flux from a point source and experimental data.
\end{abstract}

KEYWORDS: industrial fires, flame height, radiation, fire spread, model-scale tests.

\section{NOMENCLATURE LISTING}

\begin{tabular}{|c|c|c|c|}
\hline$A$ & area $\left(\mathrm{m}^{2}\right)$ & $T_{a}$ & ambient temperature $(\mathrm{K})$ \\
\hline$D$ & diameter $(m)$ & $T_{f}$ & radiation temperature of flame $(\mathrm{K})$ \\
\hline$D_{\text {eff }}$ & effective diameter (m) & $W$ & width $(\mathrm{m})$ \\
\hline$E_{b}$ & blackbody emissive power $\left(\mathrm{kW} / \mathrm{m}^{2}\right)$ & $X$ & ratio $H_{f} / r$ \\
\hline$E_{\mathrm{f}}$ & average emissive power of the flame $\left(\mathrm{kW} / \mathrm{m}^{2}\right)$ & $Y$ & ratio $W_{f} / r$ \\
\hline$H_{f}$ & flame height (m) & Greek & \\
\hline$L$ & distance $(\mathrm{m})$ & $\varepsilon$ & emissivity \\
\hline$\dot{Q}$ & heat release rate $(\mathrm{kW})$ & $\sigma$ & $\begin{array}{l}\text { Stefan-Boltzmann constant } \\
\left(\mathrm{kW} / \mathrm{m}^{2} \mathrm{~K}^{4}\right)\end{array}$ \\
\hline$\dot{Q}_{\text {comb }}$ & chemical heat release rate $(\mathrm{kW})$ & $\tau$ & atmospheric transmissivity \\
\hline$\dot{Q}_{\text {rad }}$ & radiative fraction of the heat release rate $(\mathrm{kW})$ & $\phi$ & geometric view factor \\
\hline$\dot{Q}_{\text {rad,in }}^{\prime \prime}$ & thermal radiation intensity $\left(\mathrm{kW} / \mathrm{m}^{2}\right)$ & & \\
\hline & distance between radiating and receiving surface (m) & & \\
\hline
\end{tabular}

\section{INTRODUCTION}

In buildings where there are no sprinklers, the basic idea is that the building should be located and arranged so that the fire cannot spread to nearby buildings. Fires can spread to adjacent building by flying brands, direct contact of flames or convective and radiative heat transfer (incident heat flux) from the fire plume or some combination of these mechanisms. Ignition due to incident heat flux is the most common mode of fire spread between buildings and can occur at much greater distances than direct flame impingement and convection. When the flames break through the building of origin, the risk of fire spread by radiation is increased significantly. At the time when the flames penetrate through the ceiling, the flame heights can become large, resulting in a huge increase in thermal radiation to the surroundings.

The shape and height of the flames penetrating through the ceiling may vary considerably, and in windy conditions the risk for fire spread increases when the flames are projected towards the neighbouring buildings. If the width of the opening becomes very large, the flame height may decrease and at a certain ratio of diameter $(D)$ of the fire base and the flame height $\left(H_{f}\right)$, there is a risk of a breakup of the flame into many smaller fires. This phenomena has been investigated by Heskestad [1], but the tests in Heskestad's investigation were carried out to investigate 'mass fires'. Mass fires are not expected to generate high flames relative to their base dimension. This type of fires may be related to large industrial fires where 
large portions of the ceiling have collapsed. There is, however, very little information concerning flame heights and shapes of industrial fires, mainly because this type of information is usually not registered. This information is, however, critical if one would like to calculate the risk for fire spread between buildings.

In the Swedish building regulations [2], there is a regulation concerning the risk of fire spread between adjacent buildings. The requirement is as follows: the incident radiation should not exceed $15 \mathrm{~kW} / \mathrm{m}^{2}$ during a period of $30 \mathrm{~min}$. This regulation is only applicable when the building is not sprinklered. There are numerous engineering methods available to calculate flame heights, using view factors or simpler methods (point source), to calculate the risk of fire spread [3-6]. These correlations are based on tests in a laboratory environment, and work well for pool fires and wood crib fires. Fire spread in an industrial building, in particular with flames penetrating through the ceiling, may not give similar results using traditional fire engineering methods. Other related works of interest are the EN 13501-5 on external fire behaviour and also the large-scale tests carried out within the framework of the FLUMILOG project. A $860 \mathrm{~m}^{2}$ warehouse was built and deliberately set on fire, on 26 September 2008, on the site of the future European Environmental and Safety Technology Research Center (CERTES), in Oise (France). More detailed scientific information in English from these tests is found in Ref. [3].

The work presented here focuses on flames coming out of openings in the ceiling and how this affects the incident heat flux towards a neighbouring building. A flashover situation was created inside a model of an industrial building, and the flames that burst out were documented. The heat flux from the fire was then measured and compared to different calculation models available. A comparison to large scale pool fire tests using different type of radiation models was also explored. These large scale pool fire tests have not been used for such comparison before. The model-scale results and the comparisons between experiments and correlations are presented in this paper.

\section{THEORETICAL ASPECTS}

It is very difficult to obtain reliable flame height data from industrial buildings on fire. Therefore, Ingason et al. [4] made an attempt to estimate the flame heights from photos of real industrial fires to provide methodological guidance. One difficulty methodologically is the fact that the heat release rate in a real fire is never measured and therefore not known a priori.

\section{Flame Height}

In order to estimate the heat release rate, the flame height correlation given by Heskestad [5] is assumed to be a reasonable starting point. The main reason is that Heskestad's equation takes into account the effects of the fuel base through its diameter and it has been used for numerous types of applications. Estimation of the flame heights was done by observing photos from real accidents and by comparing an object with a known height in the photo. By using the flame height correlation given by Heskestad the heat release rate could be calculated:

$H_{f}=-1.02 D+0.235 \dot{Q}^{2 / 5}$

where $H_{f}$ is the flame height (m), $D$ is the diameter of the fuel base (m) and $\dot{Q}$ is the heat release rate (kW). Equation 1 applies well for well-ventilated pool fires in open space and has been validated for rack storages and other types of fuels [6] using an effective diameter of the fuel base. This equation has, however, not been applied to the estimation of flame heights in buildings with relatively large ceiling openings. For this the effective diameter, $D=D_{\text {eff }}$, can be used, defined by the following equation:

$D_{\text {eff }}=\sqrt{\frac{4 A}{\pi}}$

where $A\left(\mathrm{~m}^{2}\right)$ is the area of the ceiling opening estimated from a photo of the actual fire.

By rearranging Eq. 1 Ingason et al. were able to estimate the heat release rate between $6 \mathrm{GW}$ and $21 \mathrm{GW}$ in four out of five cases investigated. Corresponding flame heights varied from $15 \mathrm{~m}$ to $50 \mathrm{~m}$ and the ratio $H_{f} / D_{\text {eff }}$ varied between 0.1 and 0.4 . The heat release rate per unit projected area (horizontal base area of 
the fire) of the fire was found to be in the range of $0.5-1.3 \mathrm{MW} / \mathrm{m}^{2}$. For comparison, the heat release rates per unit exposed fuel area (total surface of the fuel that is burning) for mixture of solid materials in large scale is found to be in the range of $0.1 \mathrm{MW} / \mathrm{m}^{2}$ to $0.5 \mathrm{MW} / \mathrm{m}^{2}$ [7]. For pure plastics such as polystyrene foam and polyurethane foam in bench-scale tests show that these numbers can vary from about $0.4 \mathrm{MW} / \mathrm{m}^{2}$ to $1.5 \mathrm{MW} / \mathrm{m}^{2}$ [8]. Usually industrial fires consist of mixture of different materials and not only one type of material. Further, a projected area is usually less than or equal to the exposed fuel area, which means that the estimated numbers for heat release rates per unit projected area should be higher than when using exposed fuel area. In other words, the estimated heat release rate per unit projected area is expected to be close to the estimated heat release rate per unit exposed fuel area. This indicates that the heat release rates estimated from real industrial fires are reasonable, and therefore Eq. 1 should be useful for this type of calculations.

Further, Heskestad [1] has discuss his flame height correlation in relation to the ratio $H_{f} / D$. According to Heskestad, low flame height data exhibits a transition from coherent flaming to distributed flamelets when the ration $H_{f} / D$ becomes less than about 0.5 . When this transition occurs, the air induced or entrained by combustion, if shared by all the fuel vapours, will dilute the vapours below their ability to burn. Based on this consideration, Heskestad speculates that mass fires in sufficiently large homogenous fuel beds may only be possible as distributed localized fires. Experiments carried out by Heskestad [1], using wood fibreboard arranged to produce a square array measuring $7.32 \mathrm{~m}$ on each side, confirmed that luminous flames exhibited an initial tendency to break up into distributed flamelets near $H_{f} / D=0.52$, being fully broken up near $H_{f} / D=0.34$. Heskestad was able to go down to $H_{f} / D=0.04$ in his experiments, where the entire burner surface showed flickering blue flamelets racing back and forth. These ratios are in the same range as the values obtained from real cases $(0.1-0.4)$. Therefore, Heskestad's observations from fires with low $H_{f} / D$ values are of great interest for the study presented here, and indicate that Eq. 1 can be used for industrial buildings after the flames have penetrated through a large portion of the ceiling.

Therefore, it was decided to investigate the validity of Heskestad Eq. 1 further for industrial buildings by using model-scale experiments.

\section{Incident Heat Flux}

Mudan and Croce [9] present different methods for the calculation of the incident heat flux to an adjacent object. They presented two thermal radiation models. The first is the point source radiation model, and the other is the solid flame radiation model using view factors. The first model assumes that the flame can be represented by a small source of thermal energy, that the energy radiated from the flame is a specified fraction of the energy released during combustion and that the thermal radiation intensity varies proportionately with the inverse square of the distance from the source. Expressed mathematically, radiant intensity at any distance from the source is given by [9]:

$\dot{Q}_{r a d, i n}^{\prime \prime}=\frac{\chi \dot{Q}_{c o m b}}{4 \pi L^{2}}$

where $\chi=\frac{\dot{Q}_{\text {rad }}}{\dot{Q}_{\text {comb }}}$ is the fraction of total heat release that is radiated away and $L$ is the distance from the flame centre to the observer in metres. This means the distance $L$ is dependent on the flame height. Mudan and Croce say that while the model is elegant in its simplicity, two important limitations should be recognized. The first limitation involves the modelling of radiative output and the second is the description of the variation of the intensity as a function of the distance from the source. There is a considerable variation in the fraction of radiated energy from flames, due to smoke obstruction and combustion conditions, everything from $0.2-0.4$. A value that is often quoted is $30 \%(\chi=0.3)$ for many fuels [10]. This value is an average value for the flames, and not a local one. In reality it may vary depending on the test set-up, and if it is carried out at large-scale or model-scale.

The second model is a solid flame radiation model. The solid flame model is based on the postulation that the entire visible volume of the flame emits thermal radiation and the non-visible gases do not emit much radiation. The thermal radiation intensity, $\dot{Q}_{r a d, i n}^{\prime \prime}$, can be obtained using the following equation [9]: 
where $\tau$ is the atmospheric transmissivity ( $\tau=1$ assumed here but it may vary depending on the relative humidity and path length), $E_{\mathrm{f}}$ is the average emissive power of the flame and $\phi$ is the geometric view factor which is a measure of the decrease of the radiation at different distances. Mudan and Croce give different correlations for the view factor. In Ösesik [11] or Siegel and Howel [12] a very simple expression for the configuration factor of a parallel rectangular radiator and a remote receiver is given:

$\phi=\frac{1}{2 \pi}\left[\frac{x}{\sqrt{1+x^{2}}} \tan ^{-1}\left(\frac{y}{\sqrt{1+x^{2}}}\right)+\frac{y}{\sqrt{1+y^{2}}} \tan ^{-1}\left(\frac{x}{\sqrt{1+y^{2}}}\right)\right]$

where $X=H_{f} / r, Y=W_{f} / r, H_{f}$ is the height of rectangular (m), $W_{f}$ is the width of rectangular (m) and $r$ is the distance between radiating and receiving surface $(\mathrm{m})$. Equation 5 determines the configuration factor in one of the corners of a rectangle representing the flame volume. The distance $r$ must be at right angles to the rectangle. Configuration factors are additive, given the configuration factors of each contributing part are calculated from the same receiver [13]. The total configuration factor $\phi$ is a sum of the configuration factors of each rectangle. The emissive power of a large turbulent fire may often be approximated by the following expression [9]:

$$
E_{f}=E_{b} \varepsilon
$$

where $E_{b}$ is the blackbody emissive power, $\mathrm{kW} / \mathrm{m}^{2}$, and $\varepsilon$ is emissivity. The emissive power can vary considerably depending on the fuel type and the diameter of the flame volume. If the mean radiation temperature of the fire is known it can be converted to irradiance using the Planck's law of radiation. Thus, the blackbody emissive power, $E_{b}$ is given by [9]

$$
E_{b}=\sigma\left(T_{f}^{4}-T_{a}^{4}\right)
$$

where $T_{f}$ is radiation temperature of flame $(\mathrm{K}), T_{a}$ is ambient temperature $(\mathrm{K})$ and $\sigma$ is Stefan-Boltzmann constant, $\left(\mathrm{kW} / \mathrm{m}^{2} \mathrm{~K}^{4}\right)$.

Mudan and Croce [9] reported that for large fires, the numerical value of the emissivity of flames approaches unity. Therefore, the emissive power can be determined using the mean radiation temperature. There is, however, a lack of experimental data although they do report some, e.g. the emissive power $E_{f}$ of gasoline is $60-130 \mathrm{~kW} / \mathrm{m}^{2}$ (maximum) for pools varying between $1 \mathrm{~m}$ and $10 \mathrm{~m}$, of JP-5 is $30-50 \mathrm{~kW} / \mathrm{m}^{2}$ for pool fires varying between $1 \mathrm{~m}$ and $30 \mathrm{~m}$ and of ethylene $130 \mathrm{~kW} / \mathrm{m}^{2}$ for a $2.5 \mathrm{~m}$ pool fire.

Mudan and Croce reported that most hydrocarbon fuel fires become optically thick when the diameter is about $3 \mathrm{~m}$ or larger. Substantial parts of hydrocarbon fires are obscured by a thick black smoke on the outer periphery. This smoke layer absorbs a significant part of the radiation and results in very little emission to the surroundings. In fact, the smoke layer occasionally opens up, exposing the hot flame, and a pulse of radiation is emitted to the surroundings. Although the thermal radiation from black soot is low, the hot spots appearing on the flame surface due to turbulent mixing have a higher emissive power. Large eddies within the flame bring fuel to the outer edges of the fire plume and a more efficient combustion takes place on the flame surface. These luminous spots have an emissive power of about $110-130 \mathrm{~kW} / \mathrm{m}^{2}$. It is not possible to calculate the radiation field surrounding a fire with intermittent luminous spots. For example Hägglund and Persson [14] observed that the emissive power of the black smoke for pool fires with $10 \mathrm{~m}$ diameter is $20 \mathrm{~kW} / \mathrm{m}^{2}$ when the temperature is about $800 \mathrm{~K}$ [9]. 


\section{EXPERIMENTS}

\section{Model-Scale Tests}

Lönnermark and Ingason [15] presented test results from a model of an industrial building. The model, which was assumed to be in scale 1:10, was placed under an industrial calorimeter [16] in order to measure the heat release rate. The model was $6 \mathrm{~m}$ long, $3 \mathrm{~m}$ wide and $0.7 \mathrm{~m}$ high. The model was constructed with $10 \mathrm{~mm}$ calcium silica boards with density of $870 \mathrm{~kg} / \mathrm{m}^{3}$. To protect the construction the ceiling was covered by $50 \mathrm{~mm}$ insulation with an aluminium sheet facing the inside of the enclosure. The walls and floor were covered by $20 \mathrm{~mm}$ insulation.

On each of the shorter sides, a centred inlet opening measuring $0.8 \mathrm{~m} \times 0.4 \mathrm{~m}$ was located. During the tests these inlet openings were either closed, partly open (half) or fully open. In the ceiling there were four ventilation opening $(0.15 \mathrm{~m} \times 0.15 \mathrm{~m})$. These openings $(\mathrm{V} 1-\mathrm{V} 4$ in Fig. 1) were always open and represented in total $0.5 \%$ of the ceiling area. Part of the ceiling was constructed so that different larger ceiling openings could be obtained. This was done to simulate the fire burning through the ceiling. Three different sizes of the ceiling opening were used as signified by the dotted and dashed lines in Fig. 1 . In all cases the opening was $1.5 \mathrm{~m}$ wide. In the first case the opening was $0.6 \mathrm{~m}$ long (corresponding to $5 \%$ of the full ceiling area), in the second case the opening was $1.8 \mathrm{~m}$ long (corresponding to $15 \%$ of the full ceiling area) and in the final case the opening covers the full $3 \mathrm{~m}$ breadth of the ceiling (corresponding to $25 \%$ of the full ceiling area). In one case a $5 \%$ opening was centred in the ceiling.

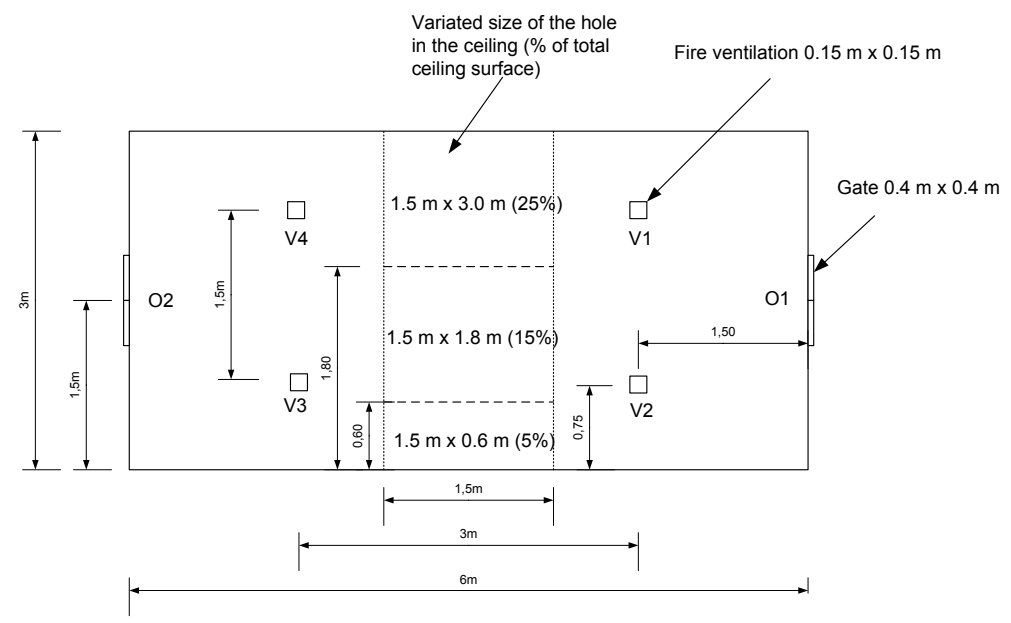

Fig. 1. Top view of the experimental set-up of the scale model. V1 to V4 are fire ventilation openings in the ceiling. $\mathrm{O} 1$ and $\mathrm{O} 2$ are openings in the short walls, $2 \mathrm{~m} \times 0.4 \mathrm{~m} \times 0.4 \mathrm{~m}$ on each side.

The fire source was always positioned centred on the floor. The main variations during the test series were the different openings and positions. The two side openings acted in most of the tests as inlet air openings. The main variation during the test series was the openings simulating the fire burned through the ceiling. The different sizes of the ceiling openings used corresponded to $5 \%, 15 \%$ and $25 \%$ of the total ceiling area. In one case there was an opening in the wall. This opening had the same area as the smallest ceiling opening.

Two different sizes of wood cribs were used: wood crib 1 (WC1) with $2.1 \mathrm{~m}$ long sticks and wood crib 2 (WC2) with $2.7 \mathrm{~m}$ long sticks. The amount of fuel, outer dimension, and spacing between the sticks were selected to simulate a distributed fire source that could burn for a suitable period of time [15]. Both wood cribs were constructed using four layers with 12 sticks in each. Two additional sticks were used to raise the wood crib a distance above the floor making it possible to place four pools with heptane $(35 \mathrm{~cm} \times 35 \mathrm{~cm})$ beneath the wood crib. Pools with heptane were used to ignite the wood cribs. The average mass of nine wood cribs used in the test series was $80.8 \mathrm{~kg}$ and the mass of wood crib 2 used was $105.4 \mathrm{~kg}$. A volume of 2.5 L of heptane was used in each pool, giving a total of $10 \mathrm{~L}$ heptane in each test. After ignition of the heptane pools the fire spread to the wood crib and the fire was then left to burn until it self-extinguished. 
The maximum heat release rate measured of $\mathrm{WC} 1$ in well-ventilated conditions in the open was $2.5 \mathrm{MW}$, whereas inside the model the maximum heat release rate was $3.68 \mathrm{MW}$. The corresponding maximum heat release rate for $\mathrm{WC} 2$ was $3.8 \mathrm{MW}$.

The heat flux was measured using Schmidt-Boelter water cooled heat flux meters. The heat flux meters were positioned in three directions from the fire (see Fig. 2). In total ten heat flux meters were used. These were calibrated for a maximum heat flux of between $10 \mathrm{~kW}$ and $100 \mathrm{~kW}$, depending on the measurement position. The height of these measurement positions was $25 \mathrm{~cm}$ above the inner surface of the ceiling of the model-scale compartment. This was $178.5 \mathrm{~cm}$ above the floor of the fire hall. Gas temperatures were also measured with thermocouples in numerous positions inside the scale model. This was done to study fire development and temperature distribution during the different tests.

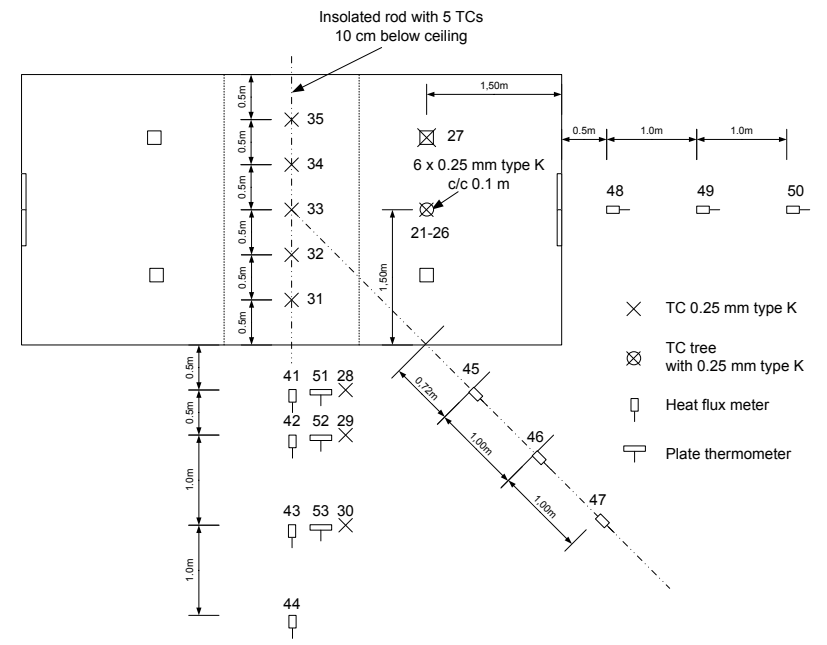

Fig. 2. Plan view of positions of measurement sensors, including channel numbers.

\section{Large-Scale Pool Fire Tests}

There is not much data available on measured heat fluxes from large-scale fires. Some data can be found in Ref. [17] on pool fires. Also in 1990, four large-scale pool fire tests were performed in Borås, Sweden, where the main focus was on testing different portable foam extinguishing systems [18]. Two tests with gasoline and two tests with an acetone/ethanol mixture were carried out in the open. A slight crosswind was experienced when the tests were performed, which is shown in the measured data. The open pool fire surface was $197 \mathrm{~m}^{2}$, divided into a circular part of $141 \mathrm{~m}^{2}$ and diameter of $13.4 \mathrm{~m}^{2}$, and a rectangular part of $56 \mathrm{~m}^{2}$. The effective diameter of the fuel surface area was estimated to $15.8 \mathrm{~m}$. Based on burning rate measurements, the heat release rate for the gasoline in Test 1 and Test 2 are estimated to be $621 \mathrm{MW}$ and $659 \mathrm{MW}$, respectively, assuming a combustion efficiency of 0.90 . It is more difficult to estimate the heat release rate of the acetone/ethanol mixture. The heat release rate for Test 3 and Test 4 was estimated to be about $365 \mathrm{MW}$ and $422 \mathrm{MW}$, respectively, assuming a combustion efficiency of 0.93 . These heat release rates will be used later to estimate the flame heights and calculate the heat flux from the tests. Unfortunately no observed or estimated flame heights are reported by Persson [18] for comparison.

Heat flux meters were located at different distances in direction from the pool edge. The heat flux meters used were of the Schmidt-Boelter water cooled type. In Fig. 3 the measured heat fluxes at different distance from the edge of the pool fire are shown. The level of heat flux towards the heat flux meters is considerably higher from the acetone/ethanol mixture compared to gasoline. One reason for the difference in heat flux is the smoke that covered the yellow flames in the gasoline tests. The flame heights were calculated by Eq. 1 and varied between $23 \mathrm{~m}$ and $33 \mathrm{~m}$ [7]. The measured heat fluxes will be used later to validate the point source and solid flame radiation model. 


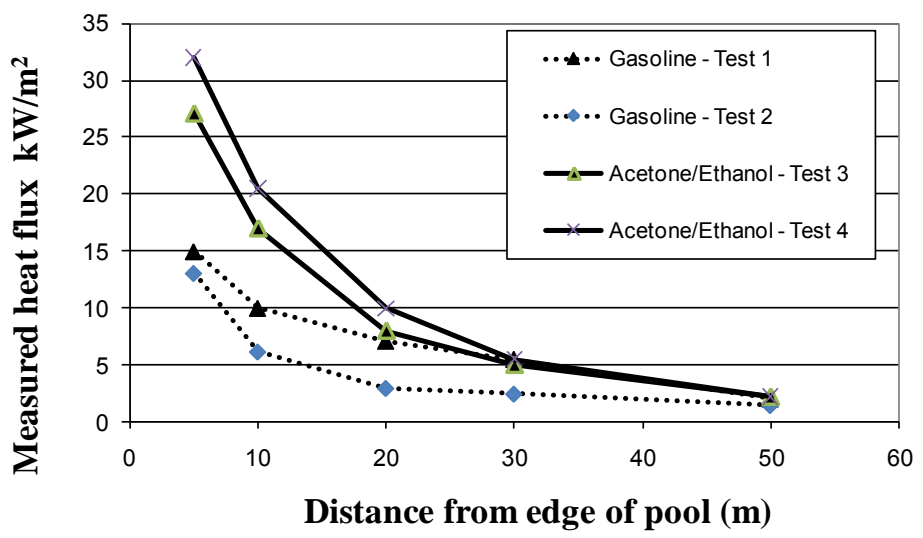

Fig. 3. Measured heat flux from different pool fires given by Persson [18].

A slight crosswind was experienced when the tests were performed. This may explain the difference in the obtained heat flux measurements for each type of fuel.

\section{RESULTS}

\section{Model-Scale}

Flame Height

The flame heights were observed for every test with the aid of a vertical ruler above the model building. This information was obtained through manual observations and analysis of video recordings. As the flame height is an important parameter obtained from these experiments, much efforts has been put into establishing reliable data. However, this type of data is always rather subjective and may cause some uncertainty in the results. In the flame height analysis only flame height observations for the fire development phase have been used. In order to compare the estimated flame heights, the parameters in Eq. 1 were used to plot the data. The flame height ratio $H_{f} / D$ was plotted as a function of $\dot{Q}^{2 / 5} / D$ as shown in Fig. 4. The effective diameter (Eq. 2) was used for the plot. The data is separated by the opening size as a percentage and the type of wood crib (WC1 or WC2), where WC2 is the larger one. There is a good correspondence to the correlation with a regression coefficient $\mathrm{R}^{2}$ equal to 0.922 . The correlation can be expressed as:

$$
\frac{H_{f}}{D}=-0.38+0.219 \frac{\dot{Q}^{2 / 5}}{D}
$$

Sometimes when the fire base is very long compared to the width, it may be better to use the shorter side of the fire base. This has been done and in Fig. 5 the data is plotted by using $D=W$, where $W$ is the shorter side of opening. Despite the fact that the data show a very similar correspondence, we obtain a slightly better regression coefficient, of $\mathrm{R}^{2}=0.930$. The correlation in this case becomes: 


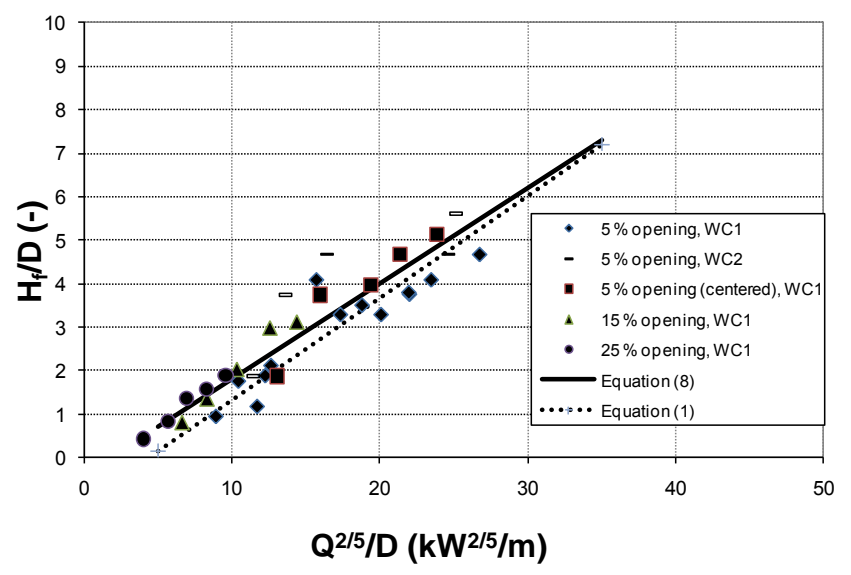

Fig. 4. The flame height correlation based on effective diameter of the opening $\left(D=D_{e f f}\right)$.

$\frac{H_{f}}{W}=-0.5+0.21 \frac{\dot{Q}^{2 / 5}}{W}$

The constants in Eqs. 8 and 9 are slightly different than in Eq. 1 but the difference is not high enough to justify them for use to calculate flame heights in industrial buildings. Heskestad's well-known equation should be used instead. Further, the correspondence between Eq. 9 shown in Fig. 5 and Eq. 1 appears to be a better correlation than between Eq. 8 shown in Fig. 4 and Eq. 1. In the case of a very long buildings, the use of the width as a characteristic length scale is indicated.

Another observation is that the maximum flame height ratio $H_{f} / D$ is higher than 0.5 for all the model-scale tests. The maximum ratio ranged between 0.5 and 10 for the test series. This explains why we did not observe any type of break-up of the flames into smaller flames in the openings. As expected, the lowest values of $H_{f} / D$ was found for the larger openings ( $15 \%$ and $25 \%$, respectively).

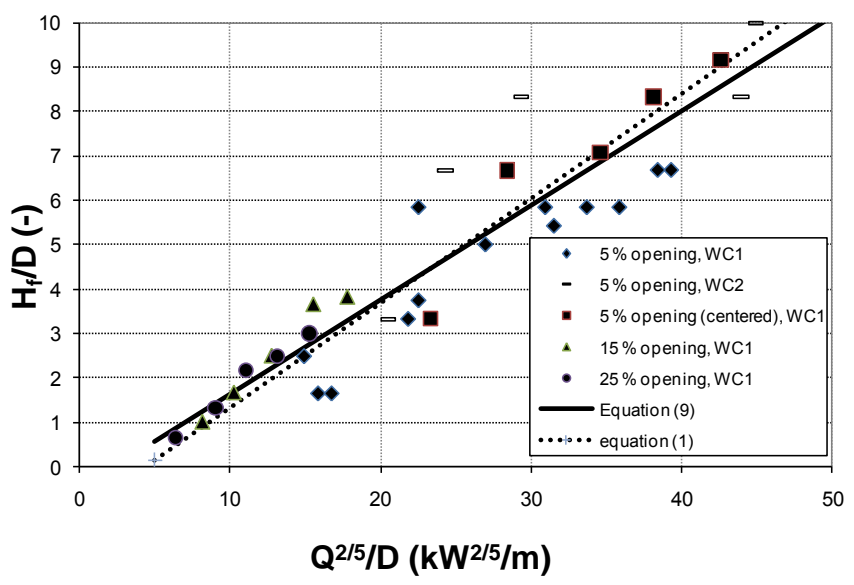

Fig. 5. The flame height correlation based on the width of the opening $(D=W)$.

\section{Radiation Models}

In order to investigate the accuracy of the radiation models, a comparison of the measured values was carried out with the heat flux meters. First, a comparison was carried out using the observed flame height. The distances were taken from the centre of the flame. For example a distance of $0.3 \mathrm{~m}$ was added for the $5 \%$ opening, $0.9 \mathrm{~m}$ for the $15 \%$ opening and $1.5 \mathrm{~m}$ for the $25 \%$ opening, respectively, to the heat flux meter $0.5 \mathrm{~m}$ from the wall. The distance $L$ in Eq. 3 is the distance from the heat flux meter to a given height at the flame volume. Usually this distance should be calculated as the diagonal distance from the heat flux 
meter up to half the flame length. Using Pythagoras' rule, we can calculate the distance $L$. The HRR is known for each test, so the only parameter to calculate is $L$.

It is known [19] that the radiation along a centreline of a flame is nearly constant up to about half the flame height (constant flame area), and decreases rapidly down to a value that is about $1-5 \%$ of the maximum value at the flame tip. The same results may be observed when the excess gas temperature is measured along a vertical plume centreline [20]. Below about half the flame height (constant flame region), the excess gas temperatures is approximately $800{ }^{\circ} \mathrm{C}\left(E_{f} \sim 80 \mathrm{~kW} / \mathrm{m}^{2}\right)$, but falls in the region of intermittent flaming to about $320{ }^{\circ} \mathrm{C}\left(E_{f} \sim 7 \mathrm{~kW} / \mathrm{m}^{2}\right)$ at the boundary of the buoyant plume. It can be argued that it is more appropriate to position the centre of radiance lower, in the range of $1 / 4-1 / 2$ of the flame height. By changing the ratio we found that the best agreement between measured and calculated was obtained when $1 / 4$ of the flame height was chosen. The results are shown in Fig. 6. The agreement was found to be much better, and the model scale data showed that the use of $1 / 4$ of the flame height instead of $1 / 2$ for calculating $L$ was better represented.

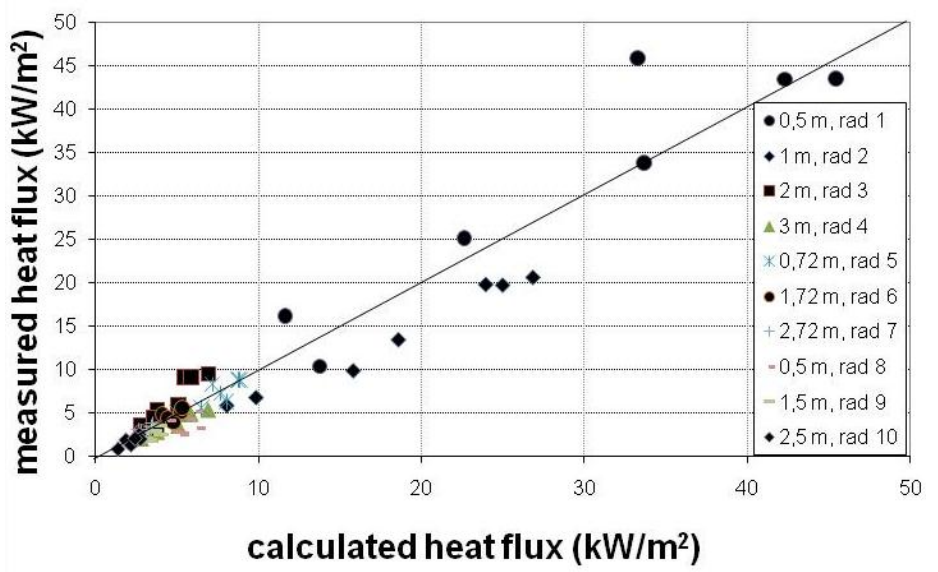

Fig. 6. The maximum measured heat flux compared to the calculated heat flux (using Eq. 3) using $1 / 4$ of the flame height for calculation of the distance.

A comparison was also done using the view factor method (solid flame model) represented by Eqs. 4 to 7 . In this case calculations and comparison were only performed for the heat flux meters positions that are perpendicular to the long wall of the building, i.e., the measuring points that are $0.5 \mathrm{~m}, 1 \mathrm{~m}, 2 \mathrm{~m}$ and $3 \mathrm{~m}$, respectively, from the long wall of the model building. The results are shown in Fig. 7. We assume that $\tau=1, \epsilon=0.9$ and the view factor is calculated by Eq. 5 assuming the height is equal to the flame height. The gas temperature $T_{f}$ is put equal to $900{ }^{\circ} \mathrm{C}$. The results are more scattered close to the wall, but become more consolidated as the distance increases.

If we compare these two methods, we can conclude that using $1 / 4$ of the flame height when calculating the diagonal distance to the flame in the point source model yields the best results. There is correspondingly more scatter in the results when using the view factor method, especially close to the fire source. The distances used here would correspond to $5 \mathrm{~m}, 10 \mathrm{~m}, 20 \mathrm{~m}$ and $30 \mathrm{~m}$ in large scale. Therefore, a comparison of radiation models based on large scale data at distances which corresponds to what is obtained in the model scale tests is also investigated. 


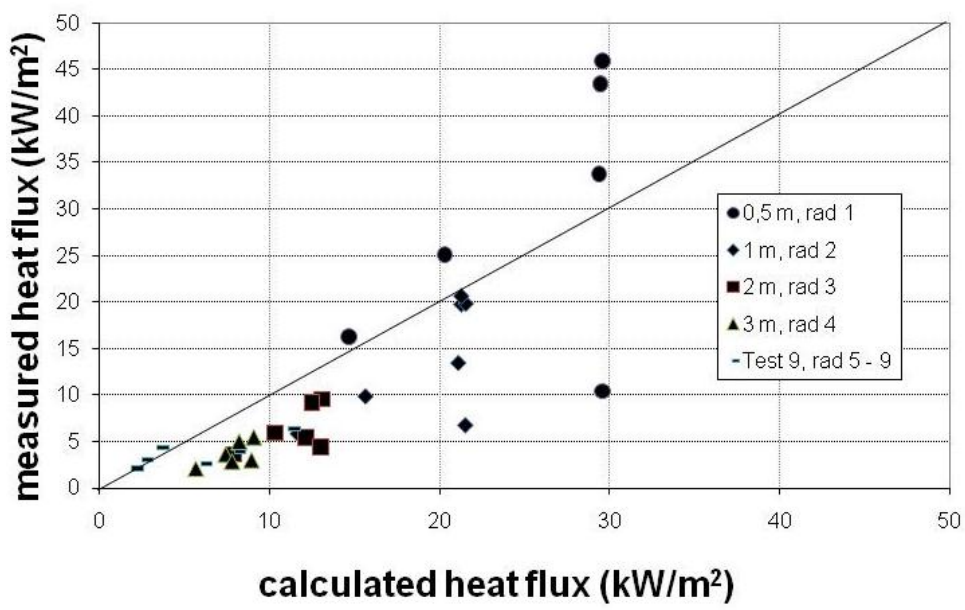

Fig. 7. The maximum measured heat flux compared to calculated heat flux using the view factor method.

\section{Large-Scale Tests}

\section{Radiation Models}

Firstly, a comparison with a point source radiation model using Eq. 3 was carried out. The basic data for the calculations can be found in Table 1. The area of the pool was estimated to be $197 \mathrm{~m}^{2}$ and the effective diameter $15.8 \mathrm{~m}$. This diameter is used in the calculations of the length $L$ from the measuring points up to the centre of the flame volume.

Table 1. Calculated values for the Swedish pool fire tests.

\begin{tabular}{|l|r|r|r|r|r|r|}
\hline Test & \multicolumn{1}{|c|}{$\begin{array}{c}\mathbf{m}^{\prime \prime} \\
\left(\mathbf{k g} / \mathbf{s} \cdot \mathbf{m}^{\mathbf{2}}\right)\end{array}$} & $\begin{array}{c}\boldsymbol{H}_{\boldsymbol{c}} \\
(\mathbf{M J} / \mathbf{k g})\end{array}$ & $\begin{array}{l}\text { Combustion }_{\text {efficiency }^{\mathbf{a}}} \\
(\mathbf{M W})\end{array}$ & $\begin{array}{c}\boldsymbol{H _ { f }} \\
(\mathbf{m})\end{array}$ & $\chi$ \\
\hline Test 1 gasoline & 0.080 & 43.7 & 0.9 & 621 & 33 & 0.12 \\
\hline Test 2 gasoline & 0.085 & 43.7 & 0.9 & 659 & 34 & 0.12 \\
\hline Test 3 acetone/ethylene & 0.076 & 26.1 & 0.93 & 365 & 23 & 0.37 \\
\hline Test 4 acetone/ethylene & 0.088 & 26.1 & 0.93 & 422 & 26 & 0.37 \\
\hline
\end{tabular}

${ }^{\mathrm{a}}$ Assumed values

The parameter that was not known was the ratio $\chi$, which is the fraction of combustion energy resulting in radiation and the combustion efficiency. For gasoline $\chi$ is much lower than the expected 0.3 as discussed previously. It has been observed in large hydrocarbon liquid fires that substantial parts of the fire are obstructed by thick black smoke on the outer periphery of the fire. This smoke layer absorbs a significant part of the radiation and results in very little emission to the surroundings. This was also the case in Persson's [18] experiments with gasoline pool fire. One should note that Test 2, was affected by the wind in such a way that the heat flux was clearly reduced, as can be seen in Fig. 3. The same approach was used for the tests with acetone/ethylene. The value of $\chi$ that was found to fit the data best was 0.37 .

Table 2. Values used to calculate the heat flux using the view factor method when comparing to the tests performed by Persson [18].

\begin{tabular}{|l|c|c|c|}
\hline Test & $\epsilon$ & $\boldsymbol{E}_{\boldsymbol{b}}\left(\mathbf{k W} / \mathbf{m}^{\mathbf{2}}\right)$ & $\boldsymbol{E}_{\boldsymbol{f}}\left(\mathbf{k W} / \mathbf{m}^{\mathbf{2}}\right)$ \\
\hline Test 1 gasoline & 0.47 & 74.7 & 35.1 \\
\hline Test 2 gasoline & 0.47 & 74.7 & 35.1 \\
\hline Test 3 acetone/ethylene & 1.0 & 74.7 & 74.7 \\
\hline Test 4 acetone/ethylene & 1.0 & 74.7 & 74.7 \\
\hline
\end{tabular}




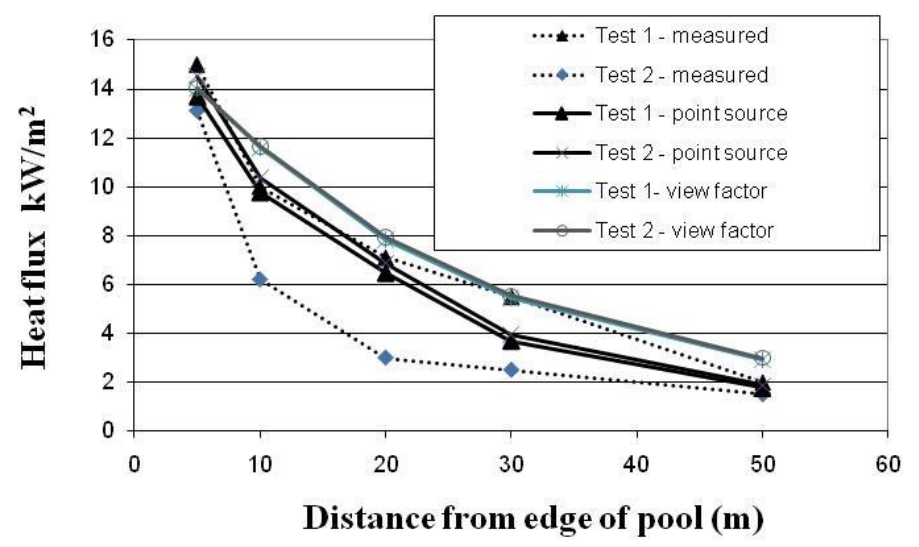

Fig. 8. Comparison of measured and calculated heat flux (point source and view factor model) for gasoline pool fires in the experiments presented by Persson [18].

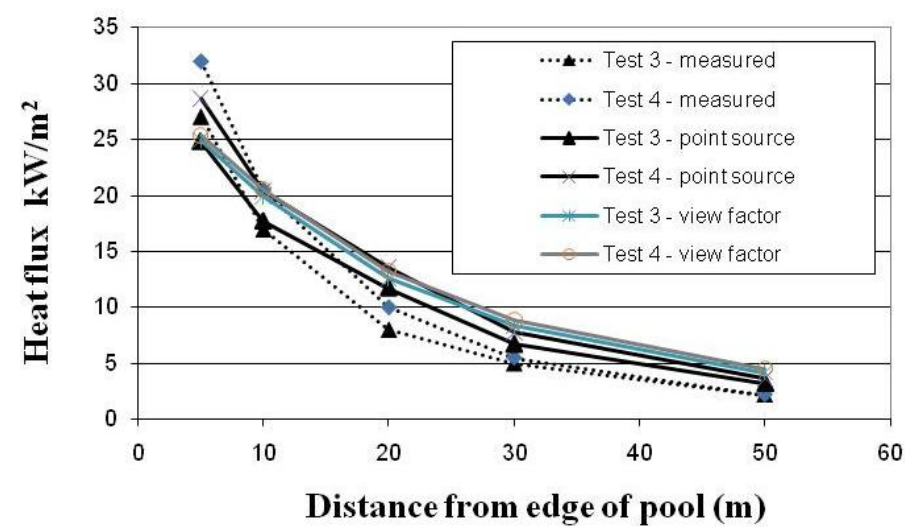

Fig. 9. Comparison of measured and calculated heat flux (point source and view factor model) for acetone/ethanol mixture in the experiments presented by Persson[18].

The second method tested to calculate the heat flux at different distances from the fire source was the solid flame radiation model represented by Eqs. 4 to 7 . There are numerous parameters in these equations that are uncertain and difficult to determine. There are several assumptions that are valid for both fuels: the atmospheric transmissivity $\tau$ is set to one, the radiation temperature $T_{f}=800{ }^{\circ} \mathrm{C}$ and the ambient temperature $T_{a}=20^{\circ} \mathrm{C}$. Other parameters where determined in order to fit the data. The flame heights are the same as calculated in Table 1. In Table 2, a summary of the values obtained is given, and in Fig. 8 and Fig. 9, a plot of the results is given for the both fuels. Here half the flame height gave much better agreement with the measured heat flux. Using $1 / 4$ of the flame height did not yield acceptable results, the values became about the twice the values shown in Fig. 8 and Fig. 9. There are, however, some uncertainties related to this fact, as the flame length was not measured in Persson's tests.

Hägglund and Persson [14] found that for pool fires that are $10 \mathrm{~m}$ in diameter, the emissive power is $E_{f}=20 \mathrm{~kW} / \mathrm{m}^{2}$ when the flames are covered by black smoke. The results given here indicate that the value of $35 \mathrm{~kW} / \mathrm{m}^{2}$ (see Table 2) for gasoline is reasonable. It was reported by Persson [18] that the flames were surrounded by black smoke, but there were also some luminous spots appearing occasionally. Mudan and Croce gave an example of a hydrocarbon pool fire with $80 \%$ black smoke and $20 \%$ luminous spots, where they calculate the emissive power to be $42 \mathrm{~kW} / \mathrm{m}^{2}$. Such an estimate is said to be consistent with the wideangle radiometer measurements conducted on JP-4, JP-5 and gasoline fires [9].

In general, the agreement between the measured and calculated is reasonable when the values of $\chi$ have been determined. The chosen values appear also to be reasonable compared to values found in the literature, i.e. values varying between 0.2 and 0.4 . A value of $\chi$ between 0.25 and 0.36 for ethylene is 
found in Ref. [9], whereas no corresponding value is given for gasoline. The gasoline fire was covered by black smoke, indicating that the amount of energy radiated away decreased compared to if it had not been covered by smoke. A value of $\chi=0.12$ is, therefore, probably quite reasonable here but the values of $\chi$ obtained from the experimental data represents both the flame and the fire plume. he calculated values for both fuels appear to follow the reduction in relation to the distance from the fire quite well. This show that the simple point source method is fairly accurate, if one can determine the value of $\chi$ for each case.

The emissive power of $74 \mathrm{~kW} / \mathrm{m}^{2}$ obtained for acetone/ethylene is difficult to assess. The calculated values for both fuels appear to follow the reduction relative to the distance from the fire particularly well. The point source method seems to give slightly better correspondence close to the fire source. In summary, we can say that the emissive power for the gasoline fuel appears to be reasonable and the reduction of the radiation using the point source method follows the measured data reasonably well. The view factor method also yields reasonable values.

\section{CONCLUSIONS}

The flame height model given by Heskestad works well for industrial buildings and the point source model gives reasonable values within the range analysed $(5 \mathrm{~m}$ to $50 \mathrm{~m}$ ). The view factor method gives satisfactory results but there are more parameters to determine, which introduces a certain uncertainty. The point source model gives a slightly better description of the distance dependency of the radiation reduction compared to the view factor method. We found that $1 / 4$ of the flame height was a better parameter to use in the model scale tests, and $1 / 2$ the flame height in the large scale test. Using half the flame height is the traditional method used, and we therefore recommend to continue in this manner.

There are some aspects that still need to be addressed, but have not been included in this study. The effects of external wind on the flame height geometry are an issue that needs to be better addressed for industrial building fires.

\section{REFERENCES}

[1] Heskestad, G., (1991) A reduced-scale mass fire experiment, Combustion and Flame, 83: 293301. http://dx.doi.org/10.1016/0010-2180(91)90076-N

[2] BBR, "Regelsamling för byggande", Boverkets byggregler 2006.

[3] Thauvoy, C., Russo, P., Blanchet, J.-M., Duplantier S., Kruppa, J., Muller, A., Patej, S., Taveau, J., and Zhao, B., "Method for calculating heat fluxes from a warehouse fire", Performance Based Code Conference Lund, Sweden, 2010.

[4] Ingason, H., Tuovinen, H., and Lönnermark, A., "Industrial fires - A literature survey", SP Technical Research Institute of Sweden, SP Report 2010:17, Borås, Sweden, 2010.

[5] Heskestad, G., (1983) Luminous Heights of Turbulent Diffusion Flames, Fire Safety Journal, 5: 103-108, http://dx.doi.org/10.1016/0379-7112(83)90002-4

[6] Heskestad, G., "Fire Plumes, Flame Height, and Air Entrainment". In The SFPE Handbook of Fire Protection Engineering (P.J. DiNenno, ed.), National Fire Protection Association, 2-1 - 2-20, Quincy, MA, USA, 2008.

[7] Ingason, H., "Fire Testing in Road and Railway Tunnels". In Flammability testing of materials used in construction, transport and mining (V. Apted, ed.), Woodhead Publishing, 231-274, 2006.

[8] Babrauskas, V., “(b) The Effects of FR Agents on Polymer Performance”. In Heat Release in Fires (V. B. a. S.J. Grayson, Ed.), Elsevier Applied Science, 423 - 446, 1992.

[9] Mudan, K.S., and Croce, P.A., "Fire Hazard Calculations for Large Open Hydrocarbon Fires". In The SFPE Handbook of Fire Protection Engineering (P. J. DiNenno, ed.), The National Fire Protection Association, 1995. 
[10] Tewardson, A., "Generation of Heat and Gaseous, Liquid, and Solid Products in Fires". In The SFPE Handbook of Fire Protection Engineering (P. J. DiNenno, ed.), National Fire Protection Association, 3-109 - 3-194, Quincy, MA, USA, 2008.

[11] Ösisik, M. N., Basic Heat Transfer, McGraw-Hill Book Company, 1979.

[12] Siegel, R., and Howell, J. R., Thermal Radiation Heat Transfer, $3^{\text {rd }}$ ed., Hemisphere Publishing Corporation, 1992.

[13] Law, M., "Heat Radiation from Fires and Building Separation", Department of Scientific and Industrial Research and Fire Offices' Committee Joint Fire Research Organization, Fire Research Technical Paper No. 5, London, 1963.

[14] Hägglund, B., and Persson, L.-E., "The Heat Radiation from Petroleum Fires", FOA, FOA Rapport C 20126-D6(A3), Stockholm, Sweden, 1976.

[15] Lönnermark, A., and Ingason, H., "Fire Spread between Industrial Premises", SP Technical Research Institute of Sweden, Borås, Sweden, 2010.

[16] Dahlberg, M., "The SP Industry Calorimeter: For rate of heat release measurements up to 10 MW", SP Swedish National Testing and Research Institute, SP Report 1992:43, Borås, Sweden, 1993.

[17] Blanchat, T., and Figueroa, V., 2009. Large-Scale Open Pool Experimental Data and Analysis for Fire Model Validation and Development, Fire Safety Science 9: 105-116, http://dx.doi.org/10.3801/IAFSS.FSS.9-105

[18] Persson, H., "Basutrustning för skumsläckning - Försöksresultat och rekommendationer som underlag för dimensionering och utförande", SP Swedish National Testing and Research Institute, SP Rapport 1990:36, Borås, Sweden (in Swedish), 1990.

[19] Ingason, H., and DeRis, J., (1998) Flame Heat Transfer in Storage Geometries, Fire Safety Journal, 31: 39-60, http://dx.doi.org/ 10.1016/S0379-7112(97)00062-3

[20] Drysdale, D., An Introduction to Fire Dynamics, John Wiley \& Sons, 1994. 